\title{
The dance of death
}

I have been consulted, as a general internist, to assist in the management of an elderly and frail patient. I am asked to assess if there could be an underlying malignancy giving rise to a paraneoplastic process. It seemed unlikely to me that this was the case but I was wrong.

Physical examination reveals critical aortic stenosis, a finding confirmed by echocardiography. A computed tomography (CT) scan of the chest shows unexpectedly, to me at least, a lesion consistent with locally advanced cancer. I meet with the patient in the presence of the medical team working with him. I explain the findings, and that they show two serious illnesses. I ask the patient if he has any worry or concerns about his health, now or in the future.

I am caught dead in a most perceptive gaze.

"You're telling me I am going to die. Aren't you?" A pause. "How long have I got?"

I am now on the spot. Inwardly, I squirm. What best to say? Three to six months, maybe? And the patient has no family members present. Is this the best time to give such news? Further compounding my dilemma is that prognostic assessment is an art, not a science. A scientifically honest answer is a box and whisker plot. I can be positive and upbeat, and avoid giving an answer; hiding behind uncertainty, perhaps invoking the lack of tissue diagnosis, but benign or malignant, the esophageal lesion is nasty indeed, and an optimistically avoidant approach runs the risk of crossing over into willful deception. I can digress about different patients, different survival times, I can obfuscate the question before finally providing a highly qualified range, but I run the risk of losing credibility and looking uncertain and ignorant and failing to provide any effective guidance. Different people, different survivals, who am I to say? Or I can give a point estimate, one more likely

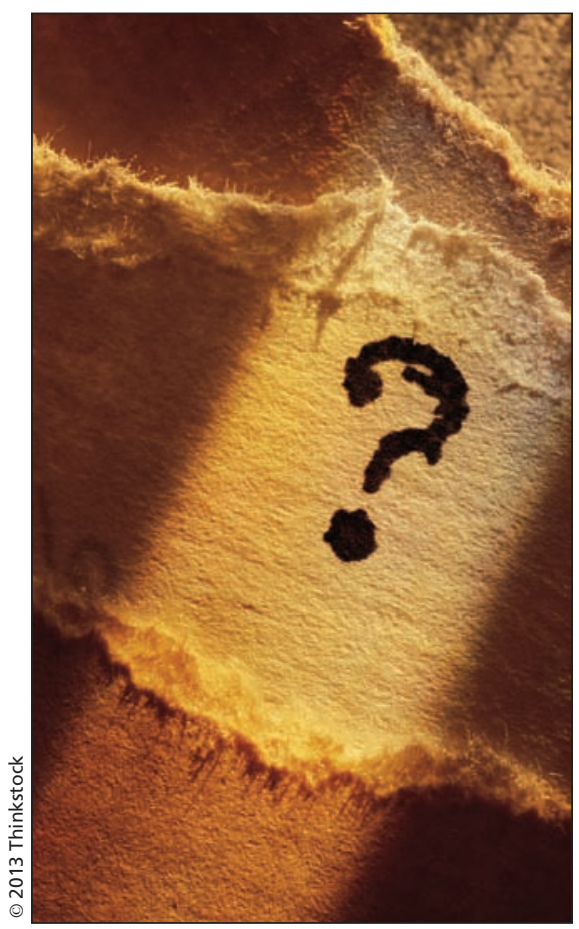

years old. How much longer can this person hope to live? How much should they hope for? Common sense provides guidance, but why not ask? So I ask. Why not go straight to the source?

"This may sound like a funny question, but how long are you hoping to live?"

"I mean these problems are serious but I have always been healthy. I figured, I dunno, maybe another ten years.'

With one exception, I think everyone in the room was surprised. I certainly was. Even my most optimistic estimate, perhaps six months, could have inadvertently crushed the patient. You don't know what you don't know. It is easy and natural for physicians, hardworking, clever, and naturally, at times, prideful creatures, to believe that our job is to answer the patient's hard questions. We get used to doing so with some measure of confidence and authority. Patients ask, and we know and answer to the best of our ability.

Less obvious is the need for embrac-

to be right than wrong, and more often, a substantial overestimation of survival. ${ }^{1}$ Easiest to overestimate, after all, who likes to look the fool?

If I go with my best estimate, months perhaps, I may well have an emotionally distraught patient, and perhaps angry family members to meet with tomorrow. It is not lost on me that I have set this process in motion without family present and am suffering for it.

In short, answering "How long have I got?" gives me ample opportunity to get it wrong and so little to get it right. Any answer I give has the potential to rupture the little bit of trust and rapport I have been able to establish.

The problem fundamentally, however, is that I don't know, not one, but two, things. First, I don't know how long the patient will live, obviously, although I can guesstimate without remorse by exercising my best judgment based upon experience. So long as I do so carefully, things are ok. Second, and more importantly, I don't know what the patient is hoping for. I just don't have a clue. Eighty-four ing how little we truly know of the other.

"Am I going to die, Doctor?"

"Have you been thinking about the possibility you could die?"

"Yes."

"Are you afraid?"

"Yes."

"Can you say what you are most afraid of?'

There are times when, as physicians, we should recognize that our questions can be infinitely more valuable than our answers.

\section{Stephen Workman MD}

General Internal Medicine

Dalhousie University

Halifax, NS

The patient characteristics are a composite.

\section{Reference}

1. Christakis NA, Lamont EB. Extent and determinants of error in doctors' prognoses in terminally ill patients: prospective cohort study. BMJ 2000; 320:469-72.

CMAJ 2013. DOI:10.1503/cmaj.122041

All editorial matter in CMAJ represents the opinions of the authors and not necessarily those of the Canadian Medical Association. 